mentation maps. While admitting their usefulness as a means of condensing many data into a compact diagram he points out their limited value unless there is correspondingly detailed information about the three-dimensional structure of the protein product.

The final chapter is devoted to speculations about the possible evolutionary significance of allelic complementation. Significance is sought in the overdominance theory of heterosis. In the thirty years since this theory first began to receive serious consideration there has been a singular lack of unambiguous evidence of its validity although there have been a number of demonstrations of its inapplicability to specific cases of heterosis. In support of the theory the author repeats conclusions current in the late forties (the most recent reference quoted being 1952) that are no longer valid. But leaving this aside the speculations founder on the complete lack of evidence that hybrid proteins have any functional superiority.

A problem that the author could have profitably considered in this chapter is why, if allelic complementation has evolutionary significance rather than being an "instructive artifact", it has become so highly developed in lower organisms whose whole vegetative existence usually takes place in the haploid state.

In a book so full of ideas the reader is bound to find himself in disagreement with the author over some of the more speculative content but this in no way detracts from the fact that "Genetic Complementation" is a critical, lucid and comprehensive review of a subject that occupies a central position in present-day genetics. It is well worth anyone's time and money.

$$
\text { J. L. Jinks. }
$$

\title{
MATRICES WITHOUT TEARS
}

MATRIX ALGEBRA FOR THE BIOLOGICAL SCIENCES (Including Applications in Statistics). S. R. Searle. John Wiley \& Sons, New York, 1966. Pp. xii +296. 75s.

To biologists, the need for a comprehensive text on matrix algebra has been apparent for some time. Matrices are increasingly used in the quantitative branches of biology, notably in population genetics and biometrical genetics, and are an essential part of any advanced course in these subjects. Dr. Searle's book is therefore welcome, and deserves particular attention.

The book opens with a description of matrices and the notation involved, elementary matrix operations, determinants and expansions. It then proceeds to discuss inversion of matrices and some aspects of the matrix theory such as rank and linear independence. These are followed by accounts of generalized inversed matrices and latent roots and vectors. A chapter is devoted to " miscellanea ", including such topics as inversion by partitioning, differential operators and direct sums and products of matrices. The two last chapters are devoted to statistical techniques which are introduced via the matrix terminology: least square estimation, linear and multilinear regression, analysis of variance, linear models and normal equations.

The text is lucidly written, the notations usually clear, and relatively little previous knowledge of algebra beyond school level is required. This last characteristic will probably add to the book's appeal to biologists. Many numerical examples are given as well as illustrations from statistics and biology. The majority of the latter are genetical problems; for instance, generation matrices under different systems of matings and estimation of 
gene effects. Genetical illustrations are also common among the useful exercises which follow each of the first eight chapters. A list of references can be found at the end of every chapter as well as a short list of books on matrix algebra.

As a whole the book is well balanced, although a more detailed account of the variance-covariance matrix would have been justified. And one last point: to geneticists, drosophila (pp. $3,3^{8}, 4^{\circ}$ ) is still Drosophila.

G. Simahen.

\section{GENETICS AS HISTORY}

THE foundations OF Genetics. F. A. E. Crew. Pergamon Press, 1966. Pp. 202. $21 \mathrm{~s}$.

A SHORT HISTORY OF GENETICS. THE DEVELOPMENT OF SOME MAIN LINES OF THOUGHT: 1864-1939. L. C. Dunn. McGraw-Hill Book Co., 1965. Pp. 261. 28 s.

In scope and subject matter these two books have much in common, but in other respects they differ widely. Professor Crew's book is aimed at science sixth-formers, and for such it furnishes in a handy format a textbook on the subject written from the historical angle. Especially valuable are the derivations given for the scientific terms and the well-arranged presentation of "Mendel: the Man", and his "Versuche über Pflanzenhybriden". Professor Dunn's book developed from a course of three lectures which he gave to the Johns Hopkins Hospital in 1964: hence it is aimed at a more informed audience and is not a textbook-style exposition of the subject.

The historical approach is very satisfactory as a means of expounding a subject which has grown up gradually on the basis of careful experimentation and restricted theorising, but where progress has followed obscure pathways and fresh hypotheses have succeeded one another pell-mell this approach tends to confuse the reader. Hence genetics is easy to present from the historical angle up to the beginning of this century. After this, particularly from 1904-09, it becomes difficult, and a full historical treatment would only confuse the uninitiated. Professor Crew has therefore wisely omitted describing Bateson's Reduplication Hypothesis and Morgan's theory of Selective Dominance, and he refers to Bateson's Presence and Absence Theory only in connection with its disproof. The result is an admirably smooth unfolding of the expansion and modification of Mendel's Principles.

Professor Dunn's book is devoted to an exposure of the main lines of thought in genetics, starting with the particulate theories of Spencer and Darwin and concluding at the end of the rg3os when these main lines of thought could be clearly perceived. With this purpose in view the author has dealt only very briefly with the pre-Mendelian hybridists and theorists and the molecular genetics of the r95os and 196os; biographical details of the personalities involved have been kept to a minimum and lengthy quotations avoided wherever possible. The result is an unusually balanced and objective account, free from chauvinistic and partisan influences. To those who are unfamiliar with the German and Dutch literature of the early days of Mendelism Professor Dunn's account of the contributions made by De Vries, Correns and Johannsen will come as a surprise, especially Correns' chromosome theory of 1902 , Dr. Vries' suggestion of 1904 that Röntgen rays be used to produce mutation, and Johannsen's brilliant little book on 